\title{
The Research on the Mechanical Properties of Concrete Mixed by the River Sand of Debris Flow in Dongchuan
}

\author{
Shaowei Yao ${ }^{a}$, Zhiying Wu \\ Hebei Provincial Key Laboratory of Inorganic Nonmetallic Materials; College of Materials Science \\ and Engineering, North China University of Science and Technology; Tangshan 063009, China \\ ayaoshaowei389@163.com
}

Keywords: river sand of debris flow, mixed sand, concrete, mechanical properties

\begin{abstract}
This article designed to make a comparison between the concrete mixed by the river sand of debris flow in Dongchuan, Yunnan province and the concrete made from the mixed sand in its working performance and mechanical property. By the numerous experiment testing results, we can find out the advantages and disadvantages of the both materials.
\end{abstract}

\section{Introduction}

The river sand of debris flow in Dongchuan, Yunnan province has the feature of less silt content, low price and abundant resources. And if we can make good use of local materials, the transportation cost and natural river sand can be greatly saved, and construction cost will reduce by $10 \%$. There are many factors which can affect the quality of concrete mixed by river sand of debris flow, such as the water-binder ratio, the kind of cement, the kind and grade of the materials, the kinds of vibrating mode, curing methods, temperature, additive, curing the environment, etc.

\section{Raw materials and experiment}

Cement: Kunming cement co., LTD. Fine aggregate: mountainous sand and manufactured sand in county Jinning of Yunnan province, and debris flow river sand in Dongchuan region. Coarse aggregate: Yunnan construction group, 5-10 $\mathrm{mm}$ stone of melon seeds, 10-20 $\mathrm{mm}$ gravel. Water: Tap water from Kunming. Fly ash: Kunming II grade fly ash of power plant. Slag: Kunming iron and steel co., LTD., S75 level. Additive: Shanghai poly carboxylic acid produced VIVID-500 super plasticizer.

The concrete mixing ratio are shown in Table 1 and Table 2. (B-binder, W-water, C-cement, S-sand, Mou-S-mountain sand, Man-S-manufactured sand, Df-S-debris flow sand, Ad- admixture) 
Table 1 Consumption of fly ash and slag are $15 \%$ of the ratio of concrete

\begin{tabular}{|c|c|c|c|c|c|c|c|c|c|c|c|}
\hline NO. & B & $\mathrm{W}$ & $\mathrm{C}$ & Sand & Mou-S & Man-S & Df-S & Stone & $\operatorname{Ad}[\%]$ & W/B & Sand ratio $[\%]$ \\
\hline $\mathrm{A} 1$ & 257 & 175 & 180 & 896 & I & l & 896 & 1052 & 1.0 & 0.68 & 46.0 \\
\hline $\mathrm{A} 2$ & 257 & 175 & 180 & 896 & 151 & 745 & I & 1052 & 1.0 & 0.68 & 46.0 \\
\hline $\mathrm{B} 1$ & 273 & 175 & 190 & 874 & l & I & 874 & 1068 & 1.1 & 0.64 & 45.0 \\
\hline B2 & 273 & 175 & 190 & 874 & 156 & 728 & l & 1068 & 1.1 & 0.64 & 45.0 \\
\hline $\mathrm{C} 1$ & 292 & 175 & 204 & 846 & l & I & 846 & 1077 & 0.5 & 0.60 & 44.0 \\
\hline $\mathrm{C} 2$ & 292 & 175 & 204 & 846 & 141 & 705 & I & 1077 & 0.5 & 0.60 & 44.0 \\
\hline D1 & 313 & 175 & 219 & 827 & I & I & 827 & 1074 & 1.6 & 0.56 & 43.5 \\
\hline D2 & 313 & 175 & 219 & 827 & 138 & 689 & I & 1074 & 1.6 & 0.56 & 43.5 \\
\hline E1 & 337 & 175 & 236 & 798 & I & I & 798 & 1080 & 0.9 & 0.52 & 43.0 \\
\hline E2 & 337 & 175 & 236 & 798 & 133 & 665 & I & 1080 & 0.9 & 0.52 & 43.0 \\
\hline $\mathrm{F} 1$ & 365 & 175 & 256 & 772 & I & I & 772 & 1088 & 1.0 & 0.48 & 41.5 \\
\hline $\mathrm{F} 2$ & 365 & 175 & 256 & 772 & 129 & 643 & I & 1088 & 1.0 & 0.48 & 41.5 \\
\hline G1 & 398 & 175 & 279 & 740 & I & I & 740 & 1087 & 0.4 & 0.44 & 40.5 \\
\hline $\mathrm{G} 2$ & 398 & 175 & 279 & 740 & 123 & 617 & I & 1087 & 0.4 & 0.44 & 40.5 \\
\hline H1 & 438 & 175 & 307 & 697 & I & I & 697 & 1090 & 0.7 & 0.40 & 39.0 \\
\hline $\mathrm{H} 2$ & 438 & 175 & 307 & 697 & 116 & 581 & I & 1090 & 0.7 & 0.40 & 39.0 \\
\hline I1 & 486 & 175 & 340 & 652 & I & I & 652 & 1087 & 1.0 & 0.36 & 37.5 \\
\hline I2 & 486 & 175 & 340 & 652 & 109 & 543 & I & 1087 & 1.0 & 0.36 & 37.5 \\
\hline $\mathrm{J} 1$ & 547 & 175 & 383 & 591 & I & I & 591 & 1087 & 1.0 & 0.32 & 35.5 \\
\hline $\mathrm{J} 2$ & 547 & 175 & 383 & 591 & 99 & 492 & I & 1087 & 1.0 & 0.32 & 35.5 \\
\hline $\mathrm{K} 1$ & 580 & 175 & 406 & 560 & 1 & I & 560 & 1086 & 0.9 & 0.30 & 34.0 \\
\hline
\end{tabular}

Table 2 Dosage of fly ash and slag were $20 \%$ of the ratio of concrete $\left(\mathrm{Kg} / \mathrm{m}^{3}\right)$

\begin{tabular}{|c|c|c|c|c|c|c|c|c|c|c|c|}
\hline NO. & B & W & $\mathrm{C}$ & Sand & Mou-S & Man-S & Df-S & Stone & $\operatorname{Ad}[\%]$ & $\mathrm{W} / \mathrm{B}$ & Sand ratio [\%] \\
\hline $\mathrm{a} 1$ & 257 & 175 & 154 & 896 & I & I & 896 & 1052 & 1.0 & 0.68 & 46.0 \\
\hline $\mathrm{a} 2$ & 257 & 175 & 154 & 896 & 151 & 745 & 1 & 1052 & 1.0 & 0.68 & 46.0 \\
\hline b1 & 273 & 175 & 164 & 874 & I & I & 874 & 1068 & 1.1 & 0.64 & 45.0 \\
\hline $\mathrm{b} 2$ & 273 & 175 & 164 & 874 & 156 & 728 & I & 1068 & 1.1 & 0.64 & 45.0 \\
\hline $\mathrm{c} 1$ & 292 & 175 & 175 & 846 & I & I & 846 & 1077 & 0.5 & 0.60 & 44.0 \\
\hline $\mathrm{c} 2$ & 292 & 175 & 175 & 846 & 141 & 705 & I & 1077 & 0.5 & 0.60 & 44.0 \\
\hline $\mathrm{d} 1$ & 313 & 175 & 188 & 827 & I & I & 827 & 1074 & 1.6 & 0.56 & 43.5 \\
\hline $\mathrm{d} 2$ & 313 & 175 & 188 & 827 & 138 & 689 & I & 1074 & 1.6 & 0.56 & 43.5 \\
\hline e1 & 337 & 175 & 202 & 798 & I & I & 798 & 1080 & 0.9 & 0.52 & 43.0 \\
\hline $\mathrm{e} 2$ & 337 & 175 & 202 & 798 & 133 & 665 & I & 1080 & 0.9 & 0.52 & 43.0 \\
\hline $\mathrm{f} 1$ & 365 & 175 & 219 & 772 & I & I & 772 & 1088 & 1.0 & 0.48 & 41.5 \\
\hline $\mathrm{f} 2$ & 365 & 175 & 219 & 772 & 129 & 643 & I & 1088 & 1.0 & 0.48 & 41.5 \\
\hline $\mathrm{g} 1$ & 398 & 175 & 239 & 740 & I & I & 740 & 1087 & 0.4 & 0.44 & 40.5 \\
\hline $\mathrm{g} 2$ & 398 & 175 & 239 & 740 & 123 & 617 & I & 1087 & 0.4 & 0.44 & 40.5 \\
\hline h1 & 438 & 175 & 263 & 697 & 1 & I & 697 & 1090 & 0.7 & 0.40 & 39.0 \\
\hline $\mathrm{h} 2$ & 438 & 175 & 263 & 697 & 116 & 581 & I & 1090 & 0.7 & 0.40 & 39.0 \\
\hline i1 & 486 & 175 & 292 & 652 & 1 & 1 & 652 & 1087 & 1.0 & 0.36 & 37.5 \\
\hline i2 & 486 & 175 & 292 & 652 & 109 & 543 & 1 & 1087 & 1.0 & 0.36 & 37.5 \\
\hline $\mathrm{j} 1$ & 547 & 175 & 328 & 591 & 1 & I & 591 & 1087 & 1.0 & 0.32 & 35.5 \\
\hline $\mathrm{j} 2$ & 547 & 175 & 328 & 591 & 99 & 492 & I & 1087 & 1.0 & 0.32 & 35.5 \\
\hline $\mathrm{k} 1$ & 580 & 175 & 348 & 560 & I & 1 & 560 & 1086 & 0.9 & 0.30 & 34.0 \\
\hline
\end{tabular}




\section{Discussion of the testing results}

The performance of the new mixing concrete.

The testing results are shown in Fig. 1 and Fig. 2.

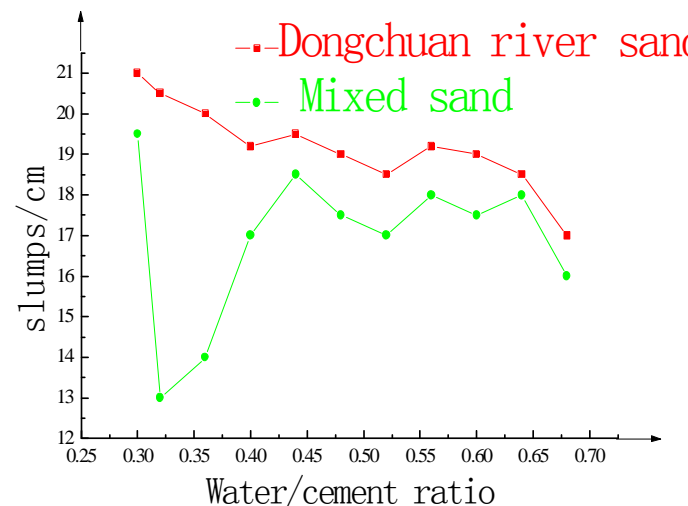

Fig. 1 Concrete slump comparison of different of kinds of sand

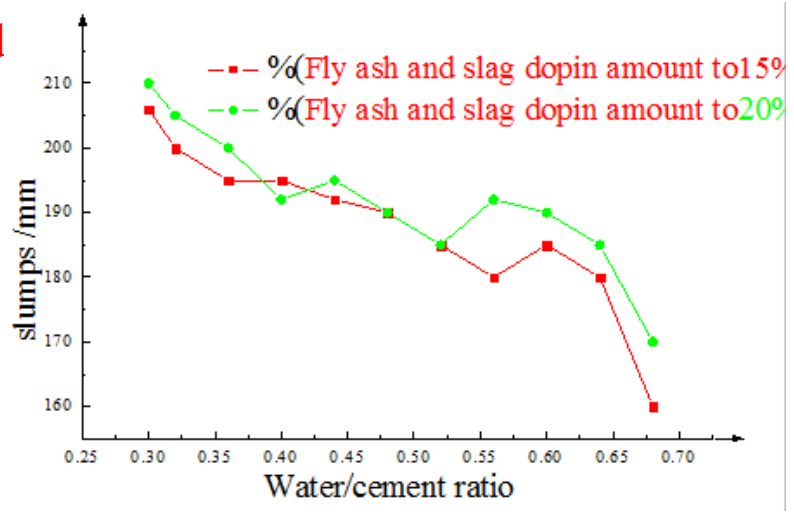

Fig. 2 Concrete slump comparison different mineral admixtures

In Fig. 1 it shows that the river sand concrete of debris flow in Dongchuan is superior to the mixed sand in slump performance under the same conditions. And with the increase of the water-binders ratio, the former has better stability than the latter. Especially the shape and surface structure have great influence on the working performance of fresh concrete. In Fig.2 it shows that mixture slump of $15 \%$ fly ash and $15 \%$ S75 ore powder is less than $20 \%$ fly ash and $20 \%$ S75 ore powder at the same water. Because of fine mineral particles can fill in the cement particles, which reduces the air void of gelled material and accordingly reduced the water filled in solid particles. This also increased the particle layer water film on the surface of the water, for the good of slurry liquidity ${ }^{[3]}$.

The intensity of the concrete

The influences of the mineral mixture on the concrete strength are shown in Fig. 3 and Fig. 4.

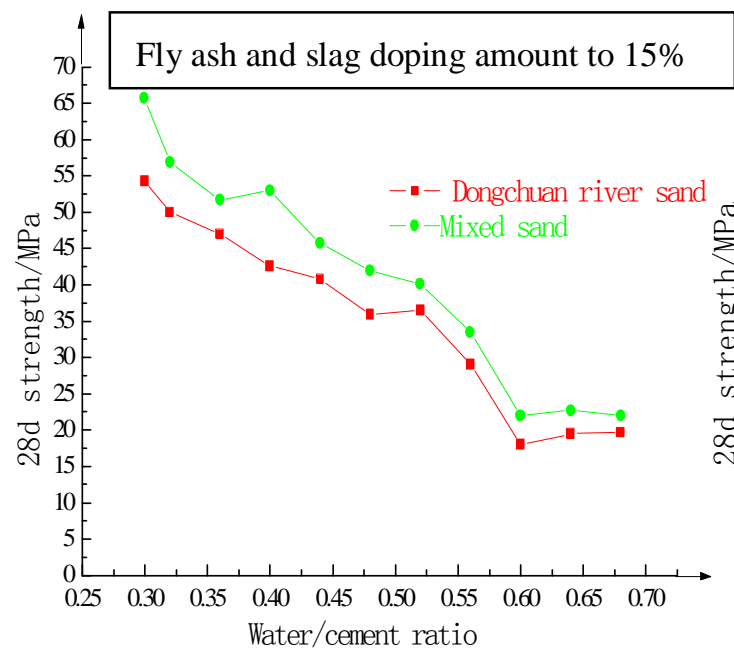

Fig. 3 Contrast of $28 \mathrm{~d}$ concrete strength of

debris flow river sand and mixing sand

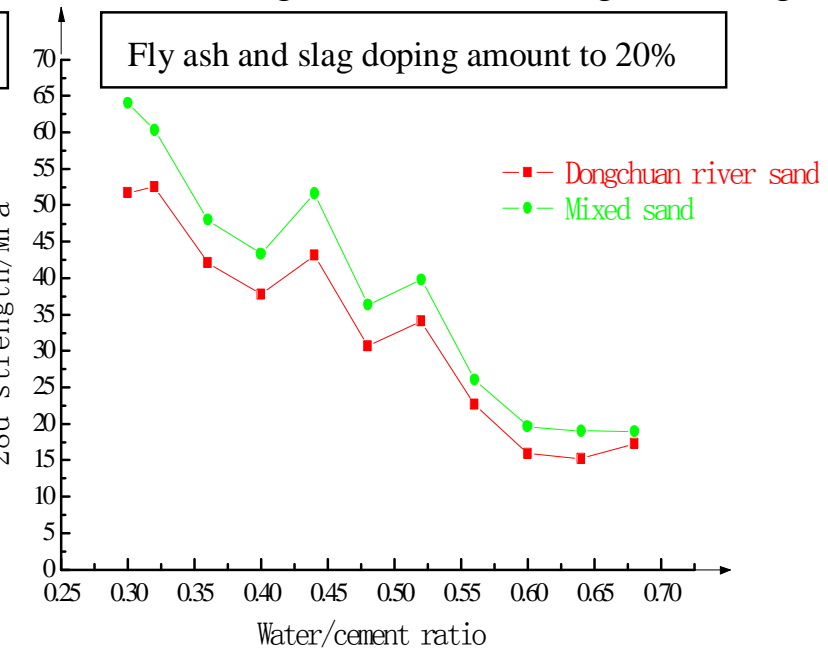

Fig. 4 Contrast of $28 \mathrm{~d}$ concrete strength of

debris flow river sand and mixing sand

In Fig. 3 and Fig. 4, under the same conditions, the strength of the river sand concrete of debris flow in Dongchuan is slightly lower than the mixed sand concrete. Dongchuan debris flow contains large 
amount of silt content, dirt and organic matter, which have disadvantages in the concrete. What's more, the stone powder in artificial sand is good to the strength of the concrete.

The impacts of different admixture on the concrete strength are shown in Fig. 5 and Fig. 6.

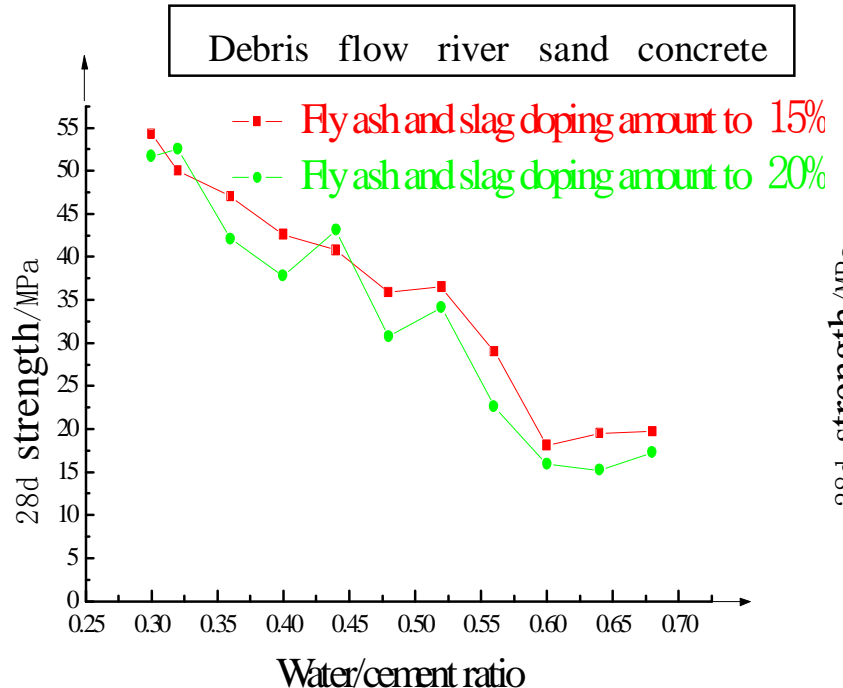

Fig. 5 Contrast of $28 \mathrm{~d}$ concrete strength of debris flow sand with admixture $15 \%$ and $20 \%$

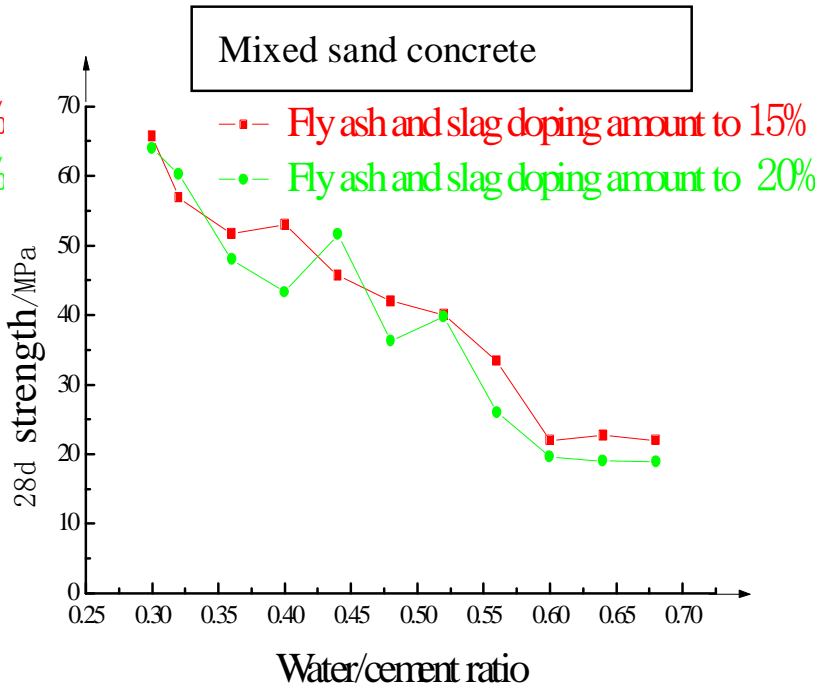

Fig. 6 Contrast of $28 \mathrm{~d}$ concrete strength of mixed sand with admixture $15 \%$ and $20 \%$

\section{Conclusions}

The strength of debris flow sand concrete is slightly lower than that of the mixed sand, but the workability is better than that of mixed sand concrete. As for debris flow sand concrete, both fly ash and slag content have influence on the working performance and mechanical properties of the concrete. When the adding amount is $15 \%$ the concrete have higher compressive strength but the working performance is a bit poor. When the adding quantity was $20 \%$ the concrete has low compressive strength but work performance is good. Concrete strength decreases with the increase of the dosage of fly ash and slag.

\section{Acknowledgements}

This work was financially supported by the Hebei Province Science and Technology Plan Project (16273706D).

\section{References}

[1]Reporters Wang Yi. Medium sand river "change" to make money to pay one hundred million yuan to buy new airport treasure Dongchuan river sand [N]. Yunnan law, (2008-12-10) (2008)

[2]Fazhou Wang, Shuguang $\mathrm{Hu}$ and Qingjun Ding, etal. The study of the high-performance composite cement concrete road [J]. China journal of highway and transport, 13 (3): 12-14(2000)

[3]Luocai Yi, Different admixtures early age period mechanical properties of concrete test research [D]. Zhejiang university (2002)

[4]Kezeng Yuan, Guibo Gao, Gongxin Li, Shitao Yan and Yongzhi Zhao. The fly ash and slag powder effect on the strength of concrete [J]. Journal of Shandong building materials, 25(2): 31-34 (2004) 